\title{
A new chitosanase gene from a Nocardioides sp. is a third member of glycosyl hydrolase family 46
}

\author{
Jean-Yves Masson, ${ }^{1,2}$ Isabelle Boucher, ${ }^{1}$ Witold A. Neugebauer, ${ }^{3}$ \\ Dindial Ramotar ${ }^{2}$ and Ryszard Brzezinski ${ }^{1}$
}

Author for correspondence: Ryszard Brzezinski. Tel: +1819821 8077. Fax: +1 8198218049 .

e-mail: rbrzezin@courrier.usherb.ca

\footnotetext{
1 Groupe de Recherche en Biologie des

Actinomycètes,

Département de Biologie, Faculté des Sciences, Université de Sherbrooke, 2500 blvd Université, Sherbrooke, QC, Canada J1K 2R1

2 Laboratoire d'Endocrinologie Moléculaire, Unité de Santé et Environnement, Centre de Recherche du CHUL, 2705, Boulevard Laurier, Ste-Foy, QC, Canada G1V 4G2

3 Département de Pharmacologie, Faculté de Médecine, Centre Hospitalier Universitaire, Sherbrooke, QC, Canada J1H 5N4
}

\begin{abstract}
Strain N106, a newly isolated soil actinomycete classified in the genus Nocardioides on the basis of its chemotaxonomy, produced an extracellular chitosanase and was highly active in chitosan degradation. A gene library of Nocardioides sp. N106 was constructed in the shuttle vector pFD666 and recombinant plasmids carrying the chitosanase gene (csnN106) were identified using the 5'-terminal portion of the chitosanase gene from Streptomyces sp. N174 as a hybridization probe. One plasmid, pCSN106-2, was used to transform Streptomyces lividans TK24. The chitosanase produced by $S$. lividans(pCSN106-2) is a protein of $29.5 \mathrm{kDa}$, with a pl 8.1, and hydrolyses chitosan by an endo-mechanism giving a mixture of dimers and trimers as endproducts. N-terminal sequencing revealed that the mature chitosanase is a mixture of two enzyme forms differing by one $\mathrm{N}$-terminal amino acid. The csnN106 gene is 79.5\% homologous to the csn gene from Streptomyces sp. N174. At the amino acid level, both chitosanases are homologous at $74.4 \%$ and hydrophobic cluster analysis revealed a strict conservation of structural features. This chitosanase is the third known member of family $\mathbf{4 6}$ of glycosyl hydrolases.
\end{abstract}

Keywords: chitosan, actinomycetes, Streptomyces, Nocardioides, chitosanase

\section{INTRODUCTION}

Chitosanases (EC 3.2.1.132) - enzymes that catalyse the hydrolysis of glycosidic bonds in chitosan (a partially or totally de-acetylated derivative of chitin) were first described by Monaghan et al. (1973). Chitosanase activities have been detected in numerous prokaryotes, fungi, and more recently, in plants (El Ouakfaoui \& Asselin, 1992). For many years, this group of enzymes remained poorly defined and the differences between the chitosanases and other enzymes able to hydrolyse partly acetylated chitosan (chitinases, lysozymes, exo- $N$-acetyl- $\beta$-D-glucosaminidases, exo- $\beta$-D-glucosaminidases) were not clear. Chitosanase was essentially distinguished from chitinase on the basis of its inability to hydrolyse fully acetylated chitin.

Abbreviations: GICN, D-glucosamine; GICNAC, $N$-acetyl- $\beta$-D-glucosamine; HCA, hydrophobic cluster analysis.

The GSDB accession number for the sequence reported in this paper is L40408.
Recently, Fukamizo et al. (1994) proposed a distinction between chitinase and chitosanase based on the specificity of cleavage of the $(1,4)-\beta$-glycosidic linkages in partially acetylated chitosan. Chitosanases were defined as glycosyl hydrolases able to hydrolyse various types of linkages in partially acetylated chitosan, but not the GlcNAc-GlcNAc bond. On the other hand, chitinases split only GlcNAcGlcNAc and GlcNAc-GlcN linkages in chitosan. Furthermore, the chitosanases were subdivided into three subclasses, characterized by the ability to split GlcNGlcN and GlcNAc-GlcN linkages (subclass I); only GlcN-GlcN linkages (subclass II) and, finally, GlcNGlcN and GlcN-GlcNAc linkages (subclass III).

Nucleotide sequences (and deduced primary amino acid sequences) are available for the chitosanase from Bacillus circulans MH-K1 (Ando et al., 1992) and from Streptomyces sp. N174 (Masson et al., 1994). Comparison of the two amino acid sequences revealed a significant homology between the $\mathrm{N}$-terminal ends of the mature proteins (amino acids 59-107 from the B. circulans chitosanase 
precursor and amino acids 41-90 from the Streptomyces sp. N174 chitosanase precursor). Despite the use of several computer programs, no homology could be detected between these chitosanases and any family of chitinases, lysozymes or hexosaminidases. On that basis, it was proposed that chitosanases form a new family of glycosyl hydrolases, distinct from other families of chitosanhydrolysing enzymes (Masson et al., 1994). This family is classified under the number 46 (B. Henrissat, personal communication).

However, the lack of homology in the middle and Cterminal segments between the $B$. circulans $\mathrm{MH}-\mathrm{KI}$ and Streptomyces sp. N174 chitosanases raises several new questions. Can these two chitosanases be considered as the first members of two distinct subfamilies? Is there any relationship between these sequence-defined subfamilies and the subclasses proposed by Fukamizo et al. (1994) on the basis of their cleavage specificity?

To answer these questions, more chitosanase genes and enzymes should be available for molecular and enzymological studies. In this paper, we describe a new chitosanase protein and its encoding gene from the actinomycete Nocardioides sp. N106, isolated from soil.

\section{METHODS}

Micro-organisms and culture conditions. Strain N106 ('N' for neutral $\mathrm{pH}$ soil) was isolated from soil during a screening programme for chitosanolytic organisms. The enrichment, detection and long-term maintenance methods were described previously (Boucher et al., 1992). For total DNA isolation, $10^{6}$ spores of N106 were used to inoculate $250 \mathrm{ml}$ Tryptic Soy Broth (TSB; Difco) and cultivated for $36 \mathrm{~h}$. Cells were harvested before the fragmentation stage.

The strains Escherichia coli DH5 $\alpha \mathrm{F}^{\prime}\left[\mathrm{F}^{\prime} \phi 80 \mathrm{~d}\right.$ lacZM15 $\Delta$ (lacZY $A-$ $\operatorname{argF}) \mathrm{U} 169 \operatorname{deo} \mathrm{R} \operatorname{rec} A 1$ end $A 1$ bsdR $17\left(\mathrm{r}_{\mathrm{K}}^{-} \mathrm{m}_{\mathrm{K}}^{+}\right) \operatorname{supE44} \lambda^{-}$thi-1 gyr $A 96$ rel $A 1$ ], obtained from Life Technologies, and Streptomyces lividans TK24, obtained from Professor D. A. Hopwood, were used as cloning hosts. E. coli strains were grown in Luria-Bertani medium (Sambrook et al., 1989). S. lividans strains were routinely propagated on TSB. For the propagation of plasmid-containing strains, media were supplemented with $50 \mu \mathrm{g} \mathrm{ml}^{-1}$ ampicillin or kanamycin. The media for $S$. lividans protoplast preparation and regeneration were as described by Hopwood et al. (1985).

For chitosanase production, spores of $S$. lividans(pCSN106-2) were used to inoculate $100 \mathrm{ml}$ TSB supplemented with $50 \mu \mathrm{g}$ kanamycin $\mathrm{ml}^{-1}$ and grown for $3 \mathrm{~d}$ at $30^{\circ} \mathrm{C}$ with shaking. Cells were harvested by 5 min centrifugation in a clinical centrifuge and a quantity of cells corresponding to $3.5 \mathrm{ml}$ pellet volume was used to inoculate $500 \mathrm{ml}$ chitosanase production medium. This consisted of $1.5 \%(\mathrm{w} / \mathrm{v})$ chitosan (practical grade, Sigma), $0.5 \%(\mathrm{w} / \mathrm{v})$ malt extract (Difco), $0.2 \%(\mathrm{v} / \mathrm{v})$ olive oil and $0.035 \%(\mathrm{v} / \mathrm{v}$ ) antifoam agent (Antifoam A, Sigma), supplemented after sterilization with $50 \mathrm{ml}$ filter-sterilized $0.1 \mathrm{M}$ MOPS buffer, $\mathrm{pH} 7$, and $0.5 \mathrm{ml}$ filter-sterilized riboflavin solution $\left(1 \mathrm{mg} \mathrm{ml}^{-1}\right)$. The culture was incubated for $72 \mathrm{~h}$ at $30^{\circ} \mathrm{C}$ with shaking (250 r.p.m.). Kanamycin was not needed in the chitosanase production medium.

Enzyme purification. The procedure of Boucher et al. (1992) was simplified, allowing rapid purification of chitosanase in two chromatographic steps. Cultures in chitosanase production medium were centrifuged. The supernatant was acidified to $\mathrm{pH}$ 4 with $5 \mathrm{M}$ acetic acid. Conductivity was adjusted to $9 \mathrm{mS}$ with distilled water. The adjusted supernatant was then applied to a $1.6 \times 20 \mathrm{~cm} \mathrm{~S}$-Sepharose Fast Flow column (Pharmacia LKB), previously equilibrated with $50 \mathrm{mM}$ sodium acetate buffer, $\mathrm{pH}$ 4 (buffer A). The flow rate was $100 \mathrm{ml} \mathrm{h}^{-1}$. The column bed was protected by an on-line, hollow fibre filter (MediaKap-5, $0.2 \mu \mathrm{m}$, Microgon). Unbound protein was washed from the column with $50 \mathrm{ml}$ buffer $A$, then a linear $160 \mathrm{ml}$ gradient from 0 to $0.6 \mathrm{M} \mathrm{NaCl}$ in buffer $A$ was applied. Chitosanase-containing fractions were identified by the standard chitosanase assay, then pooled (total volume $30 \mathrm{ml}$ ) and concentrated threefold by ultrafiltration. The next step, size-exclusion chromatography, was as described by Boucher et al. (1992).

Biochemical procedures. Chitosanase activity was assayed as described by Boucher et al. (1992) using the neocuproine reagent (Dygert $e t$ al., 1965) for reducing sugar determination. One unit (U) of enzyme is defined as the amount that liberated $1 \mu \mathrm{mol} \mathrm{D}-$ glucosamine equivalent per min under the assay conditions. For chitosanase substrate-specificity studies, the substrates were prepared as $2 \mathrm{mg} \mathrm{ml}^{-1}$ solutions or suspensions in $50 \mathrm{mM}$ sodium acetate buffer, $\mathrm{pH} 5 \cdot 5$. Protein concentration was estimated by the method of Bradford (1976), using the BioRad protein assay reagent and a BSA (Boehringer Mannheim) standard. Thin-layer chromatography (TLC) of end-products of chitosan degradation was performed as described by Neugebauer et al. (1991). The N-terminal amino acid sequence of chitosanase was determined by Edman degradation with an Applied Biosystems 473A protein sequencer.

Chemotaxonomical procedures. The diaminopimelic acid form in the cell wall and the predominant sugars in whole-cell hydrolysates were determined by TLC according to Staneck \& Roberts (1974). Mycolic acids were analysed according to Tomiyasu \& Yano (1984).

Cloning of the chitosanase gene from Nocardioides sp. N106. Chromosomal DNA from Nocardioides sp. N106 was prepared according to the method of Chater et al. (1982), digested with $B g / \mathrm{II}$ and analysed by Southern blotting using a $0.38 \mathrm{~kb} S p b \mathrm{I}-$ SacII fragment from the chitosanase gene of Streptomyces sp. N174 (Masson et al., 1994) as the hybridization probe. A strong signal was obtained in the $5-8 \mathrm{~kb}$ portion of the $B g / \mathrm{II}-$ digested DNA. A partial library of Nocardioides sp. N106 genes was constructed by ligating the $5-8 \mathrm{~kb} B g / \mathrm{II}$ fragments eluted from an agarose electrophoresis gel to $\mathrm{BamHI}$-linearized and dephosphorylated vector pFD666 (Denis \& Brzezinski, 1992). Competent $E$. coli $\mathrm{DH} 5 \alpha \mathrm{F}^{\prime}$ cells were transformed with the ligation mixture. Approximately 700 transformants were recovered on $\mathrm{LB}$ plates supplemented with $50 \mu \mathrm{g}$ kanamycin $\mathrm{ml}^{-1}$. These were screened by colony hybridization using the same probe. Four positive clones were kept for further analysis. Standard methods (Sambrook et al., 1989) were used for DNA manipulation, E. coli transformation and hybridization.

DNA sequencing. The nucleotide sequence of the $\operatorname{csn} N 106$ gene was determined on both strands by the chain-termination method (Sanger et al., 1977) with double-stranded templates obtained after subcloning appropriate segments in the pUC118 vector (Vieira \& Messing, 1987). Unidirectional deletions (Henikoff, 1984) were created to sequence segments not bordered by restriction sites. Some gaps in the sequence were filled in using synthetic oligodeoxyribonucleotides as sequencing primers. Computer-assisted analysis of the sequence was done with the University of Wisconsin Genetics Computer Group package of programs (Devereux et al., 1984). The hydrophobic cluster analysis (HCA) program (Gaboriaud et al., 1987) was obtained from Doriane. 


\section{RESULTS AND DISCUSSION}

\section{Characterization of the N106 isolate}

Actinomycete N106 was one of the most active chitosanhydrolysing micro-organims isolated during an extensive soil screening programme (Boucher et al., 1992). Strain N106 grows abundantly on Tryptic Soy Agar at $30^{\circ} \mathrm{C}$, forming aerial mycelium. Old primary hyphae break up into short, rod-like fragments with polyphosphate inclusions. Mycelium fragmentation is observed in a variety of liquid media. The LL-form of diaminopimelic acid is present in the cell walls of vegetative as well as fragmented mycelium. Galactose, glucose, mannose, ribose and rhamnose were identified in whole-cell hydrolysates. The organism is strictly aerobic. Mycolic acids were not detected. From these data, N106 was classified in the genus Nocardioides (Prauser, 1976) and will be referred as Nocardioides sp. N106.

\section{Cloning of the chitosanase gene from Nocardioides sp. N106}

In our previous work (Masson et al., 1994), we showed that the two chitosanases for which amino acid sequences were deduced from DNA sequences were rather distantly related to each other but that a reasonably well conserved module of about 50 amino acids could be identified. The nucleotide sequence encoding this conserved module is entirely included in a $0.38 \mathrm{~kb} S p h \mathrm{I}-\mathrm{SacII}$ fragment from the cloned csn gene of Streptomyces sp. N174 (Masson et al., 1994). This DNA fragment was used as a hybridization probe with total Nocardioides sp. N106 DNA digested with various restriction enzymes.

We detected one positive hybridization band per digest indicating that Nocardioides sp. N106 contains a putative chitosanase gene at least partially homologous to the Streptomyces sp. N174 DNA probe (data not shown). The 5-8 kb fragments from a BglII digest of Nocardioides sp. N106 DNA were eluted from an agarose electrophoresis gel and cloned into the Bam HI site of the vector pFD666 (Denis \& Brzezinski, 1992). After E. coli transformation, positive clones were identified by colony hybridization with the Streptomyces sp. N174 DNA probe. Four positive clones were recovered. Restriction mapping and hybridization analysis showed that these carried the same $6.5 \mathrm{~kb}$ insert in alternative orientations. Plasmid pCSN106-2 was chosen for further studies because the orientation of the insert towards the kanamycin resistance gene of the vector was the same as in the previously described plasmids pRL226 and pRL270 (Masson et al., 1993). These directed efficient expression of the Streptomyces sp. N174 chitosanase gene in a heterologous host, S. lividans TK24.

\section{Complementation of S. lividans TK24 with pCSN106-2}

S. lividans TK24 is an appropriate host for the study of heterologous chitosanase genes because it seems to lack its own chitosanase. Even on a medium containing chitosan as sole carbon source, it does not produce a typical

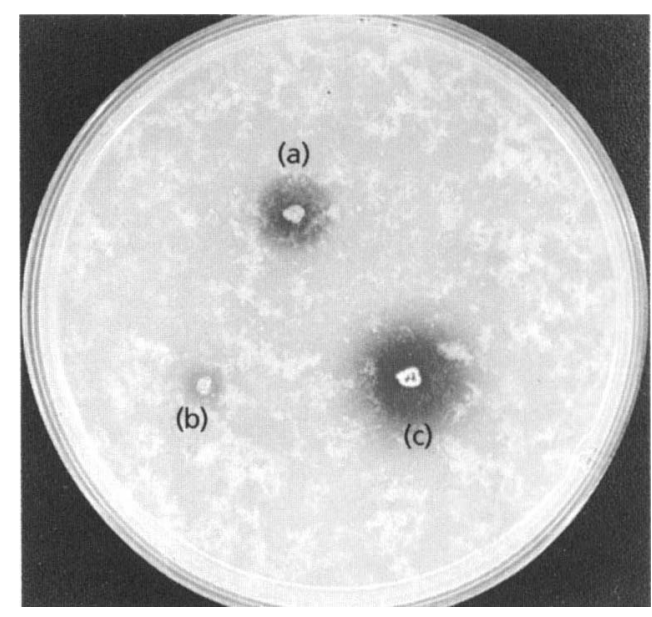

Fig. 1. Chitosan degradation zones around colonies grown on Chitosanase Detection Agar $\left(24 \mathrm{~h} ; 30^{\circ} \mathrm{C}\right.$ ). (a) S. lividans TK24; (b) S. lividans TK24(pCSN106-2); (c) Nocardioides sp. N106.

chitosanase (i.e. an enzyme acting on chitosan but not on chitin, Neugebauer et al., 1991), and the low activity of this strain against chitosan is probably due to chitinase activities (Miyashita et al., 1991) that poorly recognize chitosan as a substrate. The absence in the S. lividans TK24 genome of DNA sequences homologous to known chitosanase genes was confirmed by hybridization experiments using the same DNA probe as above.

When tested on chitosanase detection medium (Boucher et al., 1992), S. lividans TK24 gave only a weak degradation zone (Fig. 1). In contrast, the transformant TK24(pCSN106-2) hydrolysed chitosan with only slightly lower efficiency than the donor strain, Nocardioides sp. N106. It was concluded that pCSN106-2 carried a chitosanase-encoding gene. Several possibilities explain why the degradation zone around TK24(pCSN106-2) is smaller than that around the donor strain. Nocardioides could produce several chitosan-hydrolysing enzymes and only one of the corresponding genes was cloned on plasmid pCSN106-2. Multiple chitosanase activities were found in Bacillus megaterium P1 (Pelletier \& Sygusch, 1990). Alternatively, poor inducibility by chitosan of heterologous chitosanase production by $S$. lividans TK24(pCSN106-2) may be responsible (I. Boucher \& R. Brzezinski, unpublished data). Factors necessary for chitosanase gene induction could be limiting in S. lividans.

\section{Production and purification of the chitosanase}

A total quantity of $24 \mathrm{mg}$ N106 chitosanase was purified from $500 \mathrm{ml}$ culture supernatant of $S$. lividans TK24(pCSN106-2). The yield was $16 \%$ and the purification factor was 1.5 . In zymograms (El Ouakfaoui \& Asselin, 1992), the purified chitosanase co-migrated with the chitosanase produced by Nocardioides sp. N106. (not shown). The proteins also had the same isoelectric point (see below). 


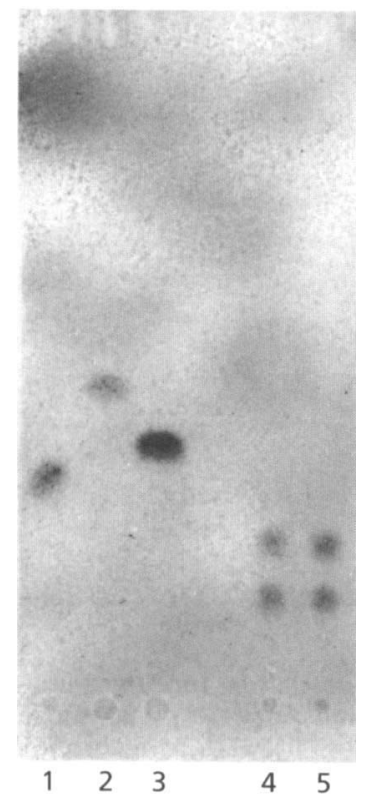

Fig. 2. TLC of end-products of chitosan Sigma (degree of acetylation $=0.21$ ) hydrolysis. Lanes: $1, N$ - $N^{\prime}$-diacetylchitobiose; 2, GlcNAC; 3, GlcN; 4, mixture of dimeric and trimeric chitooligosaccharides (end-product generated by chitosanase from Streptomyces sp. N174); 5, end-product generated by chitosanase from Nocardioides sp. N106.

\section{Preliminary characterization of the purified chitosanase}

The specific activity of the N106 chitosanase was $63 \mathrm{U}$ $\mathrm{mg}^{-1}$. The apparent molecular mass of the N106 chitosanase, determined by SDS-PAGE, was estimated to be $29 \cdot 5 \mathrm{kDa}$ by comparison with reference proteins. Analytical isoelectric focusing of the enzyme on a $\mathrm{pH}$ gradient of $6-10$ indicated a $\mathrm{pI}$ of $8 \cdot 1$.

The N106 chitosanase was specific for chitosan degradation. No hydrolysis of colloidal chitin, CM-cellulose, Avicell or heparin could be detected. Fully de-acetylated chitosan was hydrolysed at a rate of $176 \%$ that of Sigma chitosan (degree of acetylation $=0 \cdot 21$ ). The main chitosan hydrolysis products detected by TLC co-migrated with the products obtained after chitosan hydrolysis with chitosanase from Streptomyces sp. N174, identified previously (Boucher et al., 1992) as dimeric and trimeric chitooligosaccharides (Fig. 2). The absence of detectable monomeric products (either GlcN or GlcNAc) indicated that the enzyme is an endoglycosidase.

The biochemical properties of the Nocardioides sp. N106 chitosanase are thus very similar to those of the Streptomyces sp. N174 chitosanase (Boucher et al., 1992). However, the Streptomyces sp. N174 chitosanase is a slightly less alkaline protein ( $\mathrm{PI} 7 \cdot 5$ ) and its preference for fully de-acetylated chitosan is less marked (rate of hydrolysis is $123 \%$ of that of Sigma chitosan).

The first 16 amino acids at the N-terminus of the Nocardioides chitosanase were determined by the Edman method. This revealed that the purified chitosanase is a mixture of two polypeptides differing by one amino acid. About $84 \%$ of the molecules had the $\mathrm{N}$-terminal sequence AAVGLDDPHKKDIAMQ, while the remaining $16 \%$ had the sequence AVGLDDPHKKDIAMQ.

\section{Sequence analysis of the csnN106 gene}

Fig. 3 shows the sequence of a 1059 bp DNA fragment containing the $c s n N 106$ gene. The ORF of $837 \mathrm{bp}$ starts with an ATG triplet (nt 128-130) and corresponds to a 278 amino acid polypeptide. A potential RBS (GGAG) is present 7-10 nt upstream of the initiation codon. A putative streptomycete promoter (Strohl, 1992) consisting of a -35 box TTGCGC and a -10 box TTCAAT (with a spacer of $18 \mathrm{nt}$ ) was also found (nt 21-26 and 45-50).

An extensive inverted-repeat sequence, perfectly homologous to the sequence upstream from the csn gene of Streptomyces sp. N174, was located between the putative promoter and the RBS. This conserved sequence lies in the middle of an otherwise poorly conserved DNA segment. Similar sequences may be involved in regulating initiation of transcription. Experiments are in progress to ascertain the role of this inverted repeat.

The $\mathrm{N}$-terminus of the mature chitosanase is located at amino acid +1 (Fig. 4), determining a 41 amino acid signal peptide. However, a minority $(16 \%)$ of mature molecules begin with the amino acid at +2 . At present, we cannot determine if this heterogeneity is due to ambiguity in the recognition of the processing site by the signal peptidase or if it is due to some post-secretory modifications. Neither of the observed processing sites obey the (-3, -1)-rule (von Heijne, 1986). Applying the algorithm of von Heijne, the highest scores are obtained for links between amino acids -18 and -17 (highest score) or -17 and -16 (second best score). The actual processing sites are predicted with a very low probability by the algorithm. This is reminiscent of the situation found for the Streptomyces sp. N174 chitosanase (Masson et al., 1994). Other features of the N106 chitosanase signal peptide are typical: the $n$-region consisting of nine amino acids (three of them being positively charged) is followed by a hydrophobic segment of ten amino acids and a rather long $c$-region, the latter being characteristic of actinomycete signal peptides (von Heijne \& Abrahmsén, 1989) with a helix-breaking residue (proline) at position -7 .

A second, putative translation initiation in-frame ATG codon is localized $30 \mathrm{nt}$ upstream from the proposed initiation codon (Fig. 3). This codon is also preceeded by a putative RBS, GGAGA, situated at an optimal distance from the ATG triplet. The alternative initiation triplet would determine a 51 amino acid signal peptide with a 19 amino acid $n$-region including six positively charged and two negatively charged amino acids. Such a long signal peptide would still resemble some other signal peptides described for extracellular enzymes in actinomycetes; for instance that of xylanase C (Shareck et al., 1991) or $\beta$ galactosidase (Eckhardt et al., 1987), both from S. lividans. However, the proposed initiation codon determines a 


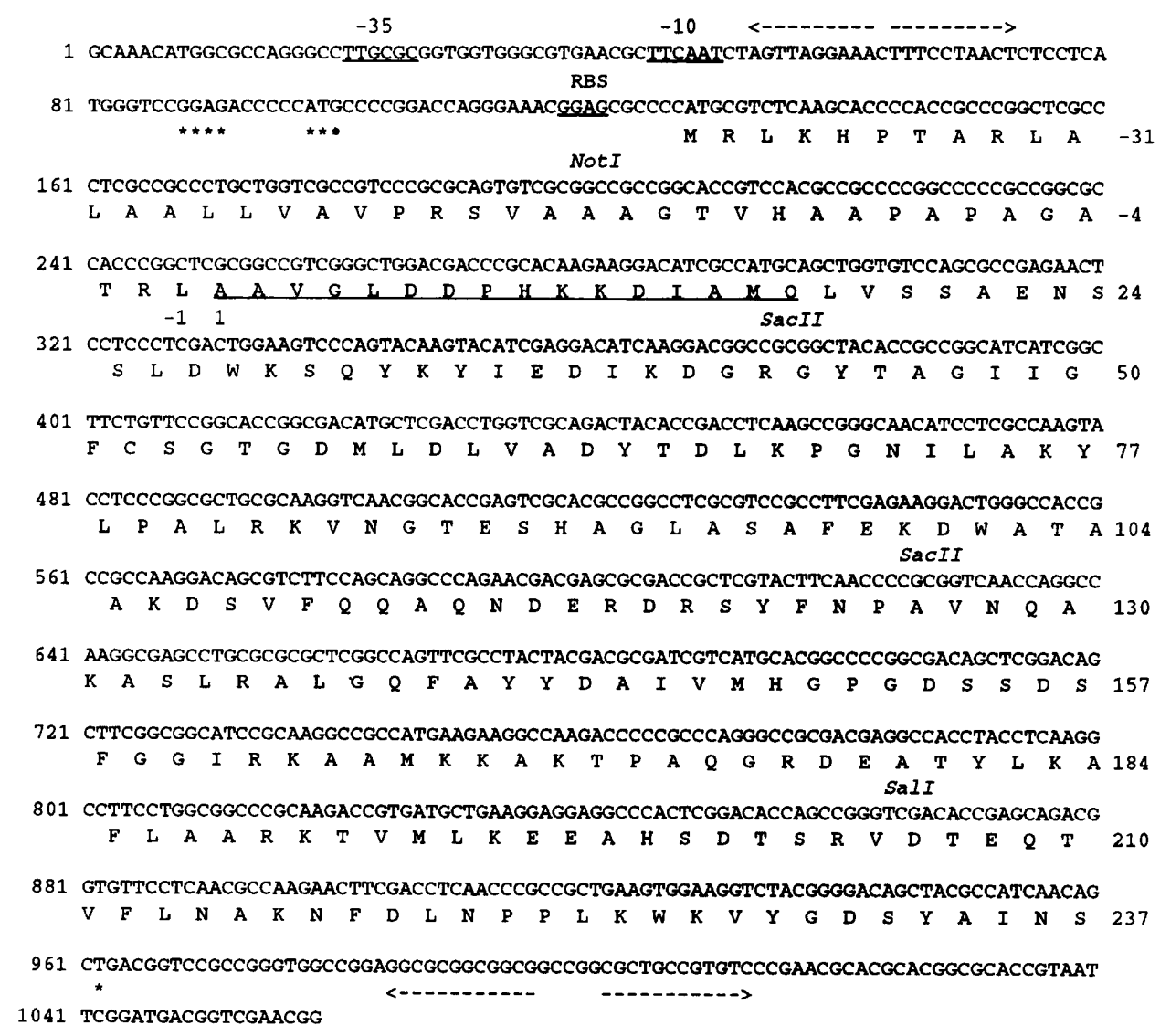

Fig. 3. Nucleotide sequence and deduced amino acid sequence of the csnN106 gene from Nocardioides sp. N106. Underlined amino acids were determined by $\mathrm{N}$-terminal amino acid sequencing of the purified chitosanase. Amino acids are numbered from the first residue of the mature chitosanase form. The putative RBS is indicated. Asterisks indicate an alternative in-frame initiation codon and the corresponding RBS. An inverted-repeat sequence upstream from the coding sequence as well as the terminator-like sequence downstream of the coding sequence are indicated by horizontal dashed arrows.

signal peptide that is much more similar to a typical actinomycete signal peptide (von Heijne \& Abrahmsén, 1989). A putative transcription terminator was found immediately downstream from the ORF (Fig. 3).

\section{Homology with other chitosanases}

The nucleotide sequence of the $c s n N 106$ gene shown on Fig. 4 is $79.5 \%$ homologous to the corresponding DNA segment of the csn gene of Streptomyces sp. N174 (nt 106-1164; Masson et al., 1994). At the amino acid level, the homology determined by the BESTFIT program at standard settings (Devereux et al., 1984) is $74 \cdot 4 \%$. Thus the N106 chitosanase is much more closely related to the Streptomyces N174 chitosanase than to the chitosanase from B. circulans MH-K1 (Ando et al., 1992), which was only $25-29 \%$ (depending of the setting of the BESTFIT program) homologous to the N174 chitosanase.

The close relationship between chitosanases from Nocardioides sp. N106 and Streptomyces sp. N174 becomes even more apparent when the sequences of both mature proteins are examined by the HCA program (Fig. 4). There is strict conservation of a clear majority of the hydrophobic clusters visualized by the program, which can be interpreted in terms of a strict conservation of the structural features in both proteins (Gaboriaud et al., 1987; Lemesle-Varloot et al., 1990).

\section{Concluding remarks}

With the addition of the chitosanase from Nocardioides sp. N106, family 46 of glycosyl hydrolases becomes better defined, including at least two members with high ( $75 \%$ ) homology at the amino acid level. The sequence of the chitosanase from $B$. circulans $\mathrm{MH}-\mathrm{K} 1$ can be aligned with the two actinomycete chitosanases to give a similarity of $45-49 \%$ according to the BESTFIT program, but these alignments are highly sensitive to the program settings and we do not consider them significant.

The only segment that is clearly homologous in all three chitosanases is the previously identified $\mathrm{N}$-terminal module (Masson et al., 1994). Interestingly, all the amino acids in this module that are conserved between the B. circulans MH-K1 chitosanase and the Streptomyces sp. N106 chitosanase are also conserved in the Nocardioides sp. N106 chitosanase. The consensus pattern we propose as the 

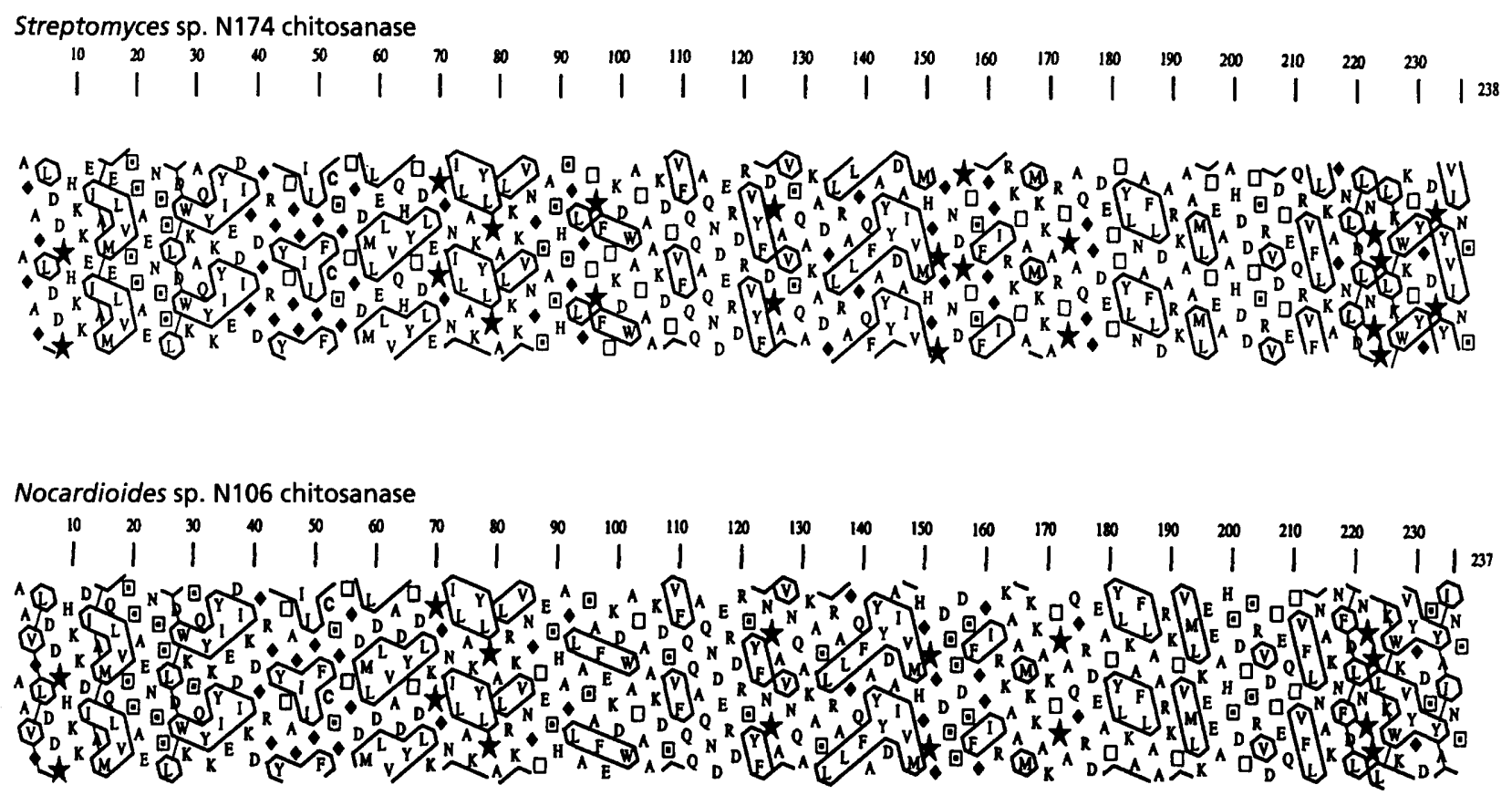

Fig. 4. Alignment of HCA plots of chitosanases from Streptomyces sp. N174 and Nocardioides sp. N106. Numbering starts from the first amino acid of the mature protein. Symbols as in Gaboriaud et al. (1987): $\star$, proline; $\bullet$, glycine; $\square$, serine; $\square$, threonine.

'family 46 signature' is (using the PROSITE notation; Bairoch, 1992): GLD-x(6)-I-x(0,1)-M-x-L-x(4)-E-x(3)-L$x-W-x(3)-Y-x-Y-x-E-D-I-x-D-x-R-G-Y-T-x-G-x(2)-G$. Recent evidence from site-directed mutagenesis experiments in our laboratory indicate that this module includes amino acids essential for the catalytic activity of chitosanase (I. Boucher \& R. Brzezinski, unpublished observations).

\section{ACKNOWLEDGEMENTS}

This research was supported by grants from the Natural Science and Engineering Research Council of Canada to R.B. and from Les Fonds de la Recherche en Santé du Québec to D.R. The authors thank Julie Vadnais for technical assistance. J.-Y.M. is a scholar of Les Fonds pour la Formation de Chercheurs et l'Aide à la Recherche du Québec.

\section{REFERENCES}

Ando, A., Noguchi, K., Yanagi, M., Shinoyama, H., Kagawa, Y., Hirata, H., Yabuki, M. \& Fujii, T. (1992). Primary structure of chitosanase produced by Bacillus circulans MH-K1. J Gen Appl Microbiol 38, 135-144.

Bairoch, A. (1992). PROSITE: a dictionary of sites and patterns in proteins. Nucleic Acids Res 20 (Suppl.), 2013-2018.

Boucher, I., Dupuy, A., Vidal, P., Neugebauer, W. A. \& Brzezinski, R. (1992). Purification and characterization of a chitosanase from Streptomyces N174. Appl Microbiol Biotecbnol 38, 188-193.

Bradford, M. M. (1976). A rapid and sensitive method for the quantitation of microgram quantities of protein utilizing the principle of protein-dye binding. Anal Biochem 72, 248-254.
Chater, K. F., Hopwood, D. A., Kieser, T. \& Thompson, C. J. (1982). Gene cloning in Streptomyces. Curr Top Microbiol Immunol 96, 69-95.

Denis, F. \& Brzezinski, R. (1992). A versatile shuttle cosmid vector for use in Escherichia coli and actinomycetes. Gene 111, 115-118.

Devereux, J., Haeberli, P. \& Smithies, O. (1984). A comprehensive set of sequence analysis programs for the VAX. Nucleic Acids Res 12, 387-395.

Dygert, S., Li, L. H., Florida, D. \& Thoma, J. A. (1965). Determination of reducing sugar with improved precision. Anal Biocbem 13, 367-374.

Eckhardt, T., Strickler, J., Gorniak, L., Burnett, W. V. \& Fare, L. R. (1987). Characterization of the promoter, signal sequence, and amino terminus of a secreted $\beta$-galactosidase from 'Streptomyces lividans'. J Bacteriol 169, 4249-4256.

El Ouakfaoui, S. \& Asselin, A. (1992). Multiple forms of chitosanase activities. Pbytochemistry 31, 1513-1518.

Fukamizo, T., Ohkawa, T., Ikeda, Y. \& Goto, S. (1994). Specificity of chitosanase from Bacillus pumilus. Biochim Biopbys Acta 1205, 183-188.

Gaboriaud, C., Bissery, V., Benchetrit, T. \& Mornon, J. P. (1987). Hydrophobic cluster analysis: an efficient new way to compare and analyse amino acid sequences. FEBS Lett 224, 149-155.

von Heijne, G. (1986). A new method for predicting signal sequences cleavage sites. Nucleic Acids Res 14, 4683-4690.

von Heijne, G. \& Abrahmsén, L. (1989). Species-specific variation in signal peptide design. FEBS Lett 244, 439-446.

Henikoff, S. (1984). Unidirectional digestion with exonuclease III creates targeted breakpoints for DNA sequencing. Gene 28, 351-359.

Hopwood D. A., Bibb, M. J., Chater, K. F., Kieser, T., Bruton, C. J., Kieser, H. M., Lydiate, D. J., Smith, C. P., Ward, J. M. \& Schrempf, 
H. (1985). Genetic Manipulation of Streptomyces: a Laboratory Manual. Norwich: John Innes Foundation.

Lemesle-Varloot, L., Henrissat, B., Gaboriaud, C., Bissery, V., Morgat, A. \& Mornon, J. P. (1990). Hydrophobic cluster analysis: procedures to derive structural and functional information from 2D-representation of protein sequences. Biochimie 72, 555-574.

Masson, J.-Y., Li, T., Boucher, I., Beaulieu, C. \& Brzezinski, R. (1993). Factors governing an efficient chitosanase production by recombinant Streptomyces lividans strains carrying the cloned chs gene from Streptomyces N174. In Chitin Enzymology, pp. 423-430. Edited by R. A. A. Muzzarelli. Ancona: European Chitin Society.

Masson, J.-Y., Denis, F. \& Brzezinski, R. (1994). Primary sequence of the chitosanase from Streptomyces sp. strain N174 and comparison with other endoglycosidases. Gene 140, 103-107.

Miyashita, K., Fujii, T. \& Sawada, Y. (1991). Molecular cloning and characterization of chitinase genes from Streptomyces lividans 66. J Gen Microbiol 137, 2065-2072.

Monaghan, R. L., Eveleigh, D. E., Tewari, R. P. \& Reese, E. T. (1973). Chitosanase, a novel enzyme. Nat New Biol 245, 78-80.

Neugebauer, E., Gamache, B., Déry, C. V. \& Brzezinski, R. (1991). Chitinolytic properties of Streptomyces lividans. Arch Microbiol 156, 192-197.

Pelletier, A. \& Sygusch, J. (1990). Purification and characterization of three chitosanase activities from Bacillus megaterium P1. Appl Environ Microbiol 56, 844-848.
Prauser, H. (1976). Nocardioides, a new genus of the order Actinomycetales. Int J Syst Bacteriol 26, 58-65.

Sambrook, J., Fritsch, E. F. \& Maniatis, T. (1989). Molecular Cloning: a Laboratory Manual, 2nd edn. Cold Spring Harbor, NY: Cold Spring Harbor Laboratory.

Sanger, F., Nicklen, S. \& Coulson, A. R. (1977). DNA sequencing with chain-terminating inhibitors. Proc Natl Acad Sci USA 74, 5463-5467.

Shareck, F., Roy, C., Yaguchi, M., Morosoli, R. \& Kluepfel, D. (1991). Sequences of three genes specifying xylanases in Streptomyces lividans. Gene 107, 75-82.

Staneck, J. L. \& Roberts, G. D. (1974). Simplified approach to identification of aerobic actinomycetes by thin-layer chromatography. Appl Microbiol 28, 226-231.

Strohl, W. R. (1992). Compilation and analysis of DNA sequences associated with apparent streptomycete promoters. Nucleic Acids Res 20, 961-974.

Tomiyasu, I. \& Yano, I. (1984). Separation and analysis of novel polyunsaturated mycolic acids from a psychrophilic, acid-fast bacterium, Gordona aurantiaca. Eur J Biochem 139, 173-180.

Vieira, J. \& Messing, J. (1987). Production of single-stranded plasmid DNA. Methods Enzymol 153, 3-11.

Received 17 March 1995; revised 6 June 1995; accepted 27 June 1995. 